\title{
Vestibular and attractor network basis of the head direction cell signal in subcortical circuits
}

\author{
Benjamin J. Clark ${ }^{\dagger}$ and Jeffrey S. Taube* \\ Department of Psychological and Brain Sciences, Center for Cognitive Neuroscience, Dartmouth College, Hanover, NH, USA
}

Edited by:

Yasser Roudi, Norwegian University of Science and Technology, Norway

Reviewed by:

Francesca Sargolini, Aix Marseille

Université - CNRS, France

Douglas Nitz, University of

California, San Diego, USA

\section{*Correspondence:}

Jeffrey S. Taube, Department of

Psychological and Brain Sciences,

Dartmouth College, 6207 Moore

Hall, Hanover, NH 03755, USA.

e-mail: jeffrey.taube@dartmouth.edu

${ }^{\dagger}$ Present address:

Canadian Centre for Behavioural

Neuroscience, University of

Lethbridge, Lethbridge, AB, Canada

T1K 3M4.
Accurate navigation depends on a network of neural systems that encode the moment-to-moment changes in an animal's directional orientation and location in space. Within this navigation system are head direction (HD) cells, which fire persistently when an animal's head is pointed in a particular direction (Sharp et al., 2001a; Taube, 2007). HD cells are widely thought to underlie an animal's sense of spatial orientation, and research over the last $25+$ years has revealed that this robust spatial signal is widely distributed across subcortical and cortical limbic areas. The purpose of the present review is to summarize some of the recent studies arguing that the origin of the HD signal resides subcortically, specifically within the reciprocal connections of the dorsal tegmental and lateral mammillary nuclei. Furthermore, we review recent work identifying "bursting" cellular activity in the HD cell circuit after lesions of the vestibular system, and relate these observations to the long held view that attractor network mechanisms underlie HD signal generation. Finally, we summarize anatomical and physiological work suggesting that this attractor network architecture may reside within the tegmento-mammillary circuit.

Keywords: entorhinal, hippocampus, head direction, spatial orientation, navigation

\section{INTRODUCTION}

Accurate navigation depends on knowledge of current spatial position and direction (Gallistel, 1990). Precisely how this information is represented in the mammalian brain is not entirely understood, although it is widely believed that the basic structure of a map-like representation, which contains the spatial relationships between landmarks and objects within the immediate environment, is formed in the limbic system (O'Keefe and Nadel, 1978; McNaughton et al., 1996, 2006). An animal's position within this neural map is thought to arise from the reciprocal connections of areas within the parahippocampal-hippocampal region; a notion that follows from the fact that this circuitry contains neurons that represent an animal's location in an environment (Moser et al., 2008), as well as neurons that encode the animal's orientation (Taube, 2007). For instance, the hippocampal CA region contains neurons that discharge as an animal passes through specific locations within an environment (Figure 1A, left) (O'Keefe and Dostrovsky, 1971). In the parahippocampal cortex, neurons also encode an animal's environmental location, although these cells differ from hippocampal "place cells" because some cells discharge in multiple locations forming interlocking equilateral triangles (Figure 1A, middle) (Hafting et al., 2005), and others fire in relation to the boundaries of an environment (Figure 1A, right) (Savelli et al., 2008; Solstad et al., 2008). These parahippocampal neurons-referred to as "grid cells" and "border cells," respectively - were first identified within the medial entorhinal cortex (Hafting et al., 2005; Sargolini et al., 2006; Savelli et al., 2008; Solstad et al., 2008), but have also been identified within the subicular complex (subiculum, Lever et al., 2009; pre- and parasubiculum, Boccara et al., 2010).
In addition to the neural signals representing spatial location, a fourth class of spatially responsive cells, called "head direction (HD) cells" (Figure 1B), provide information regarding an animal's directional orientation in space, and are thought to underlie our sense of direction (Ranck, 1984; Taube et al., 1990a). This view is derived from the fact that because different HD cells are best-tuned to different directions, a small ensemble of these cells can accurately track the moment-to-moment changes in an animal's HD over time (Johnson et al., 2005). HD cells coexist with grid cells and border cells in parahippocampal (medial entorhinal, pre- and parasubicular) cortical areas (Sargolini et al., 2006; Boccara et al., 2010). In addition, HD cells have been identified throughout the limbic system including many structures within the classical Papez circuit (Papez, 1937; reviewed in Taube, 2007). Over the last two decades, a significant amount of research has broadened our understanding of the functional organization of this HD cell system, as well as how the HD signal is generated within subcortical and parahippocampal circuits. The purpose of the present review is to summarize these findings and specifically address some of the issues concerning their network organization and the mechanisms underlying their generation.

\section{HIERARCHICAL ORGANIZATION OF HD CELL CIRCUITRY}

Although the HD cell signal is distributed across a wide range of brain regions, many of these structures are highly interconnected forming a complicated circuit with many reciprocal connections (see Figure 2). There is now considerable evidence that this interconnected circuit of HD cells is organized in a relatively hierarchical scheme (Taube, 2007). For instance, lesion studies have demonstrated that damage to cortical HD cell areas do not 


\section{A}

\section{Place Cell Grid Cell Border Cell}

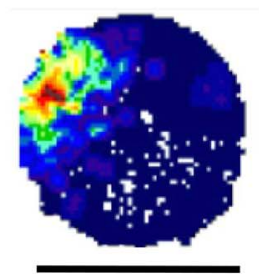

$0.7 \mathrm{~m}$

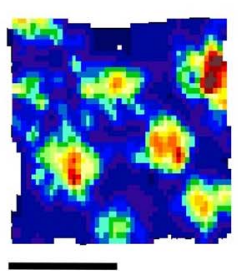

$0.7 \mathrm{~m}$

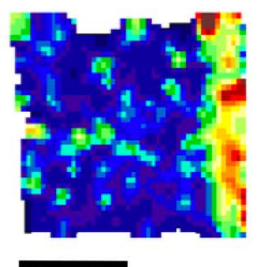

$0.7 \mathrm{~m}$

в Head Direction Cells
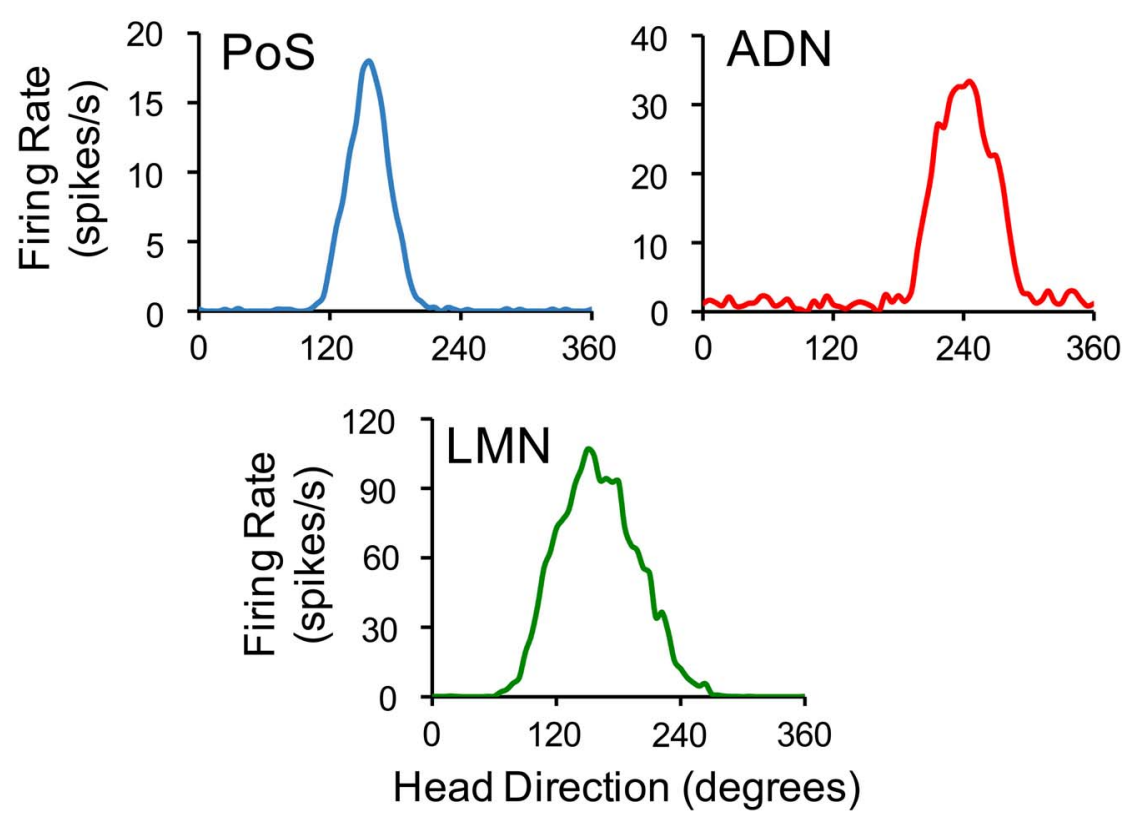

FIGURE 1 | (A) Color-coded rate maps for a hippocampal place cell, a medial entorhinal grid cell and a medial entorhinal border cell (Red, maximum firing rate; blue, minimum firing rate). (B) Firing rate by HD plots for representative HD cells recorded in the postsubiculum (PoS), anterodorsal thalamus (ADN), and lateral mammillary nuclei (LMN).
The place cell in panel (A) is based on data from Calton et al. (2003), and the grid and border cells are from Clark et al. (2011). The plots in (B) are based on data from Clark et al. (2010) (for ADN), Stackman and Taube (1998) (for LMN), and Taube et al. (1990a) (for PoS). abolish HD signal generation within subcortical structures, while lesions of subcortical HD cell regions generally abolish directional activity in cortical circuits (Table 1). The first study to provide evidence for this general principal of HD circuit organization came from Goodridge and Taube (1997) in which the anterodorsal thalamus was lesioned and cellular activity was recorded in the postsubiculum. In general, lesions of the anterodorsal thalamus completely abolished HD cell activity in the postsubiculuma finding that has recently been replicated in preliminary work showing that similar lesions abolish HD cell activity in the parasubiculum and the superficial layers of the medial entorhinal cortex (Clark et al., 2011). In contrast, lesions of the postsubiculum do not disrupt HD signal generation in subcortical structures (Goodridge and Taube, 1997; Yoder and Taube, 2008), suggesting that descending cortical input to subcortical HD cell areas plays a more limited role in HD cell processing. Much of the work that has focused on lesioning cortical structures and monitoring HD cell activity in subcortical areas is consistent with this notion (see Table 1). However, the ability of visual landmark cues to control HD cell tuning is most significantly disrupted after damage to the postsubiculum (see Yoder et al., 2011 a for review). The early work by Goodridge and Taube (1997) suggested that the postsibuculum might integrate this visual information into the HD circuit and more generally into the MEC and hippocampus (Calton et al., 2003). Recent preliminary work suggests (Yoder and Taube, 2008) that landmark information is also conveyed subcortically to HD cells in the lateral mammillary nuclei via direct projections from the postsubiculum. Indeed, the lateral mammillary nuclei may serve as one important node where landmark information is integrated with idiothetic information. In accordance with the 


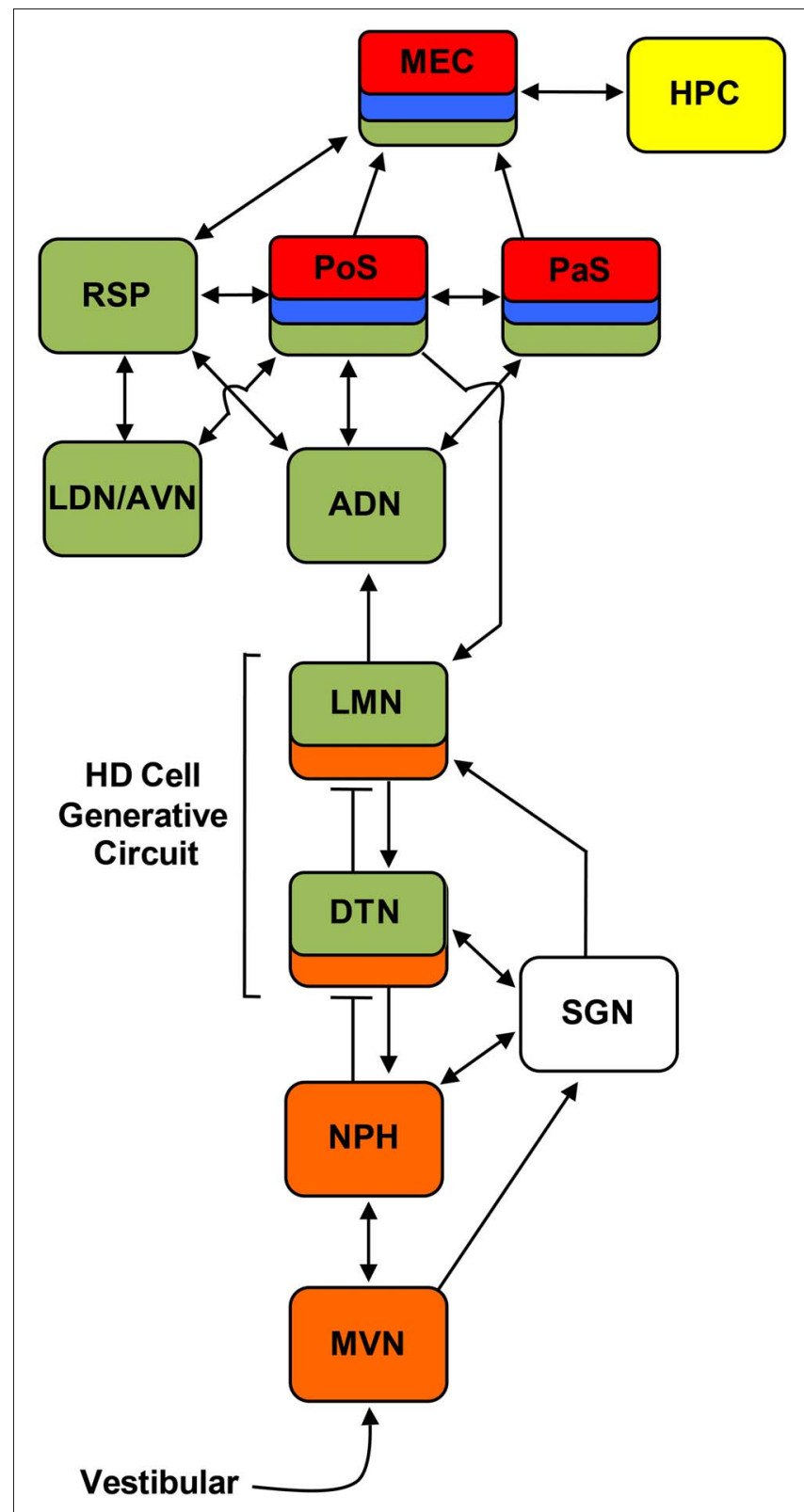

FIGURE 2 | Circuit diagram showing the principle connections between brain regions containing place cells (yellow), grid cells (red), border cells (blue), HD cells (green), and angular velocity cells (orange) (Sharp et al., 2001a; Taube and Bassett, 2003; Taube, 2007). Arrows indicate excitatory projections, and lines that end with a bar represent inhibitory projections. ADN, anterodorsal thalamus; AVN, anteroventral thalamus; DTN, dorsal tegmental nucleus; HPC, hippocampus; LDN, laterodorsal thalamus; LMN, lateral mammillary nuclei; MEC, medial entorhinal cortex; MVN, medial vestibular nuclei; NPH, nucleus prepositus hypoglossi; PaS, parasubiculum; PoS, postsubiculum; RSP, retrosplenial cortex; SGN, supragenual nucleus.

working model presented in Figure 2, damage to the postsubiculum may abolish directional activity in the medial entorhinal cortex as well as landmark control over other spatial signals within this region, given that it provides one of the most prominent inputs to this region (van Haeften et al., 1997; Kerr et al., 2007) and that postsubicular lesions disrupt landmark control in CA1 place cells (Calton et al., 2003).

Supporting the general conclusion that HD signal generation resides subcortically, several studies have shown that lesions centered on structures upstream of the anterior thalamus also eliminate directional tuning downstream (Table 1). Specifically, bilateral damage of the dorsal tegmental or lateral mammillary nuclei abolishes HD cell activity in the anterodorsal thalamus (Blair et al., 1998, 1999; Bassett et al., 2007). Further, lateral mammillary lesions abolish HD tuning in the postsubiculum, parasubiculum, and medial entorhinal cortex (Sharp and Koester, 2008). Again, lesions of the anterodorsal thalamus completely abolish directional tuning throughout the parahippocampal region, collectively indicating that given the known anatomy of these areas (see Taube, 2007 for review), the flow of information within the HD system likely follows a path from dorsal tegmental nucleus $\rightarrow$ lateral mammillary nuclei $\rightarrow$ anterodorsal thalamus $\rightarrow$ parahippocampal/retrosplenial cortex.

\section{VESTIBULAR INPUT, "BURSTY" CELLS, AND ATTRACTOR NETWORK HYPOTHESES OF HD SIGNAL GENERATION}

HD cells are strongly influenced by external and internally generated sources of information (Taube, 2007). For instance, external cues such as visual landmarks can control HD cell tuning such that a change in the orientation of a landmark can induce a similar change in the preferred directions of HD cells. In other words, HD cell preferred firing directions tend to shift in the same direction and angular distance as landmarks (Taube et al., 1990b; Taube, 1995). Although landmark information exerts a strong influence on HD cells, the directional firing preference of HD cells can be maintained even when familiar external cues are eliminated, such as in darkness or in novel environments (Taube and Burton, 1995; Goodridge et al., 1998; Stackman et al., 2003; Yoder et al., 2011b). This finding suggests that internally generated information, or idiothetic cues (i.e., vestibular, proprioception, and motor efference), can be utilized to keep track of changes in directional heading over time, a process often referred to as angular path integration. The precise sensory mechanisms underlying angular path integration are unclear, however, it was suggested very early on that the vestibular system might play a particularly important role in this process (Potegal, 1982; Taube et al., 1990b; McNaughton et al., 1991). This view follows from the simple fact that angular head velocity-a product of the mechanical properties of the semicircular canals, which are sensitive to head accelerationcan be integrated over time to yield angular displacement, as has been demonstrated in occulomotor pathways (Robinson, 1989). An estimate of current HD can, therefore, be accomplished by a vector summation of the angular displacement and the animal's previous HD. McNaughton et al. (1991) provided the first computational model that captured this notion and subsequent models (e.g., Skaggs et al., 1995; Redish et al., 1996; Zhang, 1996) have expanded on this basic principal using continuous attractor networks (Figure 3). In these models, HD cells are conceptually arranged in a ring corresponding to their preferred firing directions. Cells with preferred directions that have overlapping directional firing ranges share excitatory connections and cells with greatly different preferred directions inhibit each other. This 
Table 1 | Summary of lesion results involving the HD cell circuit.

\begin{tabular}{|c|c|c|c|c|c|}
\hline Lesion area & Recording location & HD signal & Landmark & Idiothetic & Reference \\
\hline \multirow[t]{2}{*}{ Vestibular labyrinth } & Anterodorsal thalamus & No & - & - & Stackman and Taube, 1997 \\
\hline & Postsubiculum & No & - & - & Stackman et al., 2002 \\
\hline Supragenual nuclei & Anterodorsal thalamus & No & - & - & $\begin{array}{l}\text { Clark et al., unpublished } \\
\text { observations }\end{array}$ \\
\hline Dorsal tegmental nuclei & Anterodorsal thalamus & No & - & - & Bassett et al., 2007 \\
\hline \multirow[t]{4}{*}{ Lateral mammillary nuclei } & Anterodorsal thalamus & No & - & - & Blair et al., 1998; Bassett et al., 2007 \\
\hline & Postsubiculum & No & - & - & Sharp and Koester, 2008 \\
\hline & Parasubiculum & No & - & - & Sharp and Koester, 2008 \\
\hline & Medial entorhinal cortex & No & - & - & Sharp and Koester, 2008 \\
\hline \multirow[t]{3}{*}{ Anterodorsal thalamus } & Postsubiculum & No & - & - & Goodridge and Taube, 1997 \\
\hline & Parasubiculum & No & - & - & Clark et al., 2011 \\
\hline & Medial entorhinal cortex & No & - & - & Clark et al., 2011 \\
\hline Laterodorsal thalamus & Postsubiculum & Yes & OK & Not tested & Golob et al., 1998 \\
\hline \multirow[t]{2}{*}{ Postsubiculum } & Anterodorsal thalamus & Yes & Impaired & Mildly impaired & Goodridge and Taube, 1997 \\
\hline & Lateral mammillary nuclei & Yes & Impaired & Not tested & Yoder and Taube, 2008 \\
\hline Retrosplenial cortex & Anterodorsal thalamus & Yes & Mildly impaired & OK & Clark et al., 2010 \\
\hline Medial entorhinal cortex & Anterodorsal thalamus & Yes & OK & OK & Clark and Taube, 2011 \\
\hline \multirow[t]{2}{*}{ Hippocampus } & Anterodorsal thalamus & Yes & OK & Impaired & Golob and Taube, 1997, 1999 \\
\hline & Postsubiculum & Yes & OK & Impaired & Golob and Taube, 1997, 1999 \\
\hline \multirow[t]{2}{*}{ Parietal cortex } & Anterodorsal thalamus & Yes & OK & Mildly impaired & Calton et al., 2008 \\
\hline & Medial entorhinal cortex & Yes & Not tested & Not tested & Whitlock et al., 2010 \\
\hline
\end{tabular}

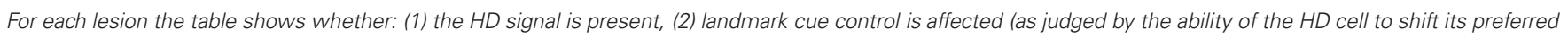

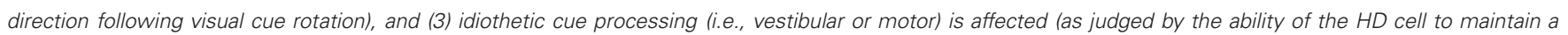

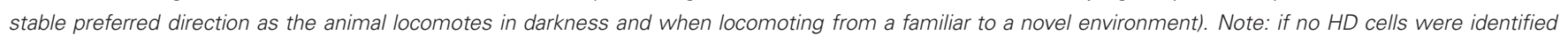
following the lesion, then it was not possible to assess landmark or idiothetic cue processing.

neural architecture forms a sustained "hill" of excitation centered on the animal's current HD. This activity hill is observed as a burst of firing when the animal's HD passes through the cell's preferred firing direction during a head turn. Angular head velocity information is commonly used to move the hill of activity around to different directions depending on changes to the animal's HD (this process is typically modeled through an additional ring of neurons that conjunctively encodes $\mathrm{HD}$ and angular head velocity; see Figure 3). A specific consequence of removing angular head velocity input is an activity hill that no longer moves along the ring in register with the animal's HD. Instead, the hill moves in different directions at different rates depending on the remaining inputs that convey information about current heading (e.g., visual and motor). In other words, neurons within the network would fire in bursts, as if the animal is passing its head through each cell's preferred firing direction. This latter feature of attractor networks, which we have termed "bursting" activity, forms an important prediction especially when considered with the lesion studies described below.

The hypothesis that vestibular information is critical for HD signal processing was first tested in a study conducted by Stackman and Taube (1997) in which anterodorsal thalamus HD cells were recorded before and after sodium arsanilate lesions of the vestibular system-a neurotoxic lesion technique that destroys hair cells throughout the vestibular labyrinth (Chen et al., 1986). In general, lesions of the peripheral vestibular system completely abolished directional activity in the anterodorsal thalamus of rats (Figure 4A). Surprisingly, the absence of HD cell activity persisted for up to 3 months (the post-lesion time period in which cell recording was monitored), strongly indicating that other sensory systems (e.g., vision or motor) were not capable of compensating for the loss of vestibular input, despite the fact that these cues can gain strong control over directional tuning (Goodridge et al., 1998; Stackman et al., 2003). An additional surprising result was the fact that Stackman and Taube did not detect burst firing in isolated units that had previously been modulated by HD. In other words, HD cells did not appear to "turn into" bursty cells following the neurotoxic lesions. As noted above, the significance of this result is derived from predictions of ring attractor models, in which an attractor that is uncoupled from its angular updating inputs should have the appearance of HD cell activity, but cell firing would be uncorrelated with the animal's HD. Because the activity hill would move around the ring attractor in random directions and at varying rates, the activity of a single cell recorded from such a network would resemble intermittent bursts of activity. Stackman and Taube identified some anterodorsal thalamus neurons that exhibited intermittent bursts of activity (e.g., Figure 4C), but because the spatial and behavioral correlates of these cells were not determined before the lesion, and because identified HD cells failed to display burst activity after lesions were produced, the authors argued against this interpretation.

Subsequent work by Stackman et al. (2002) replicated the general finding that vestibular input is necessary for HD cell 


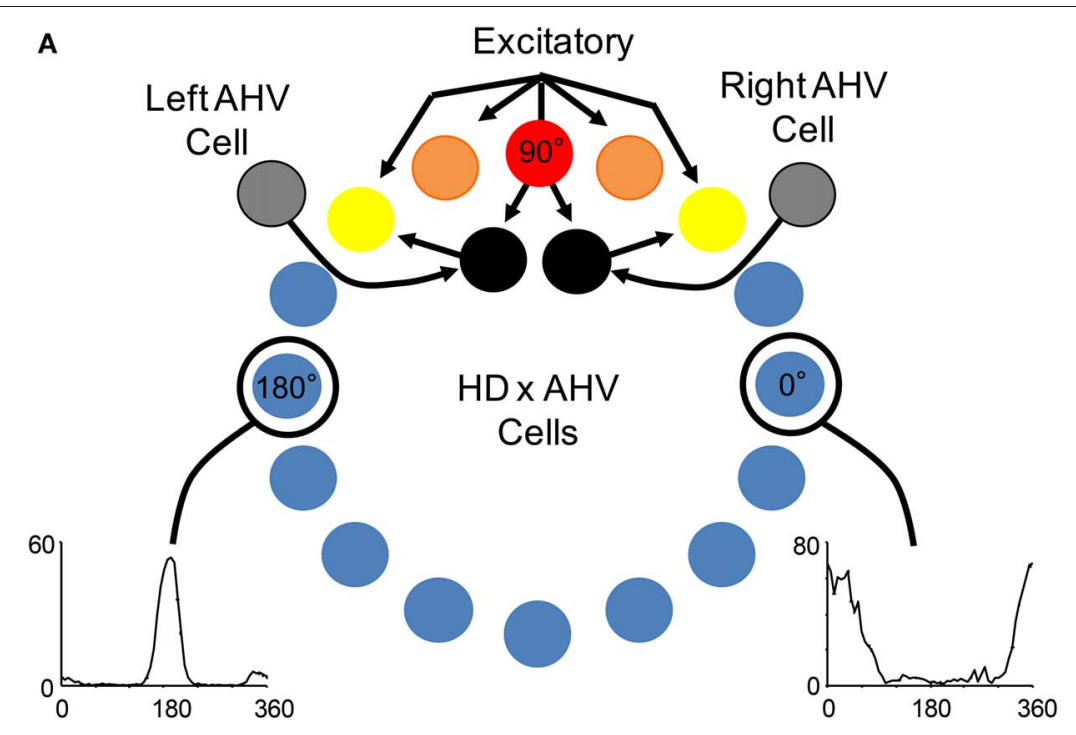

B

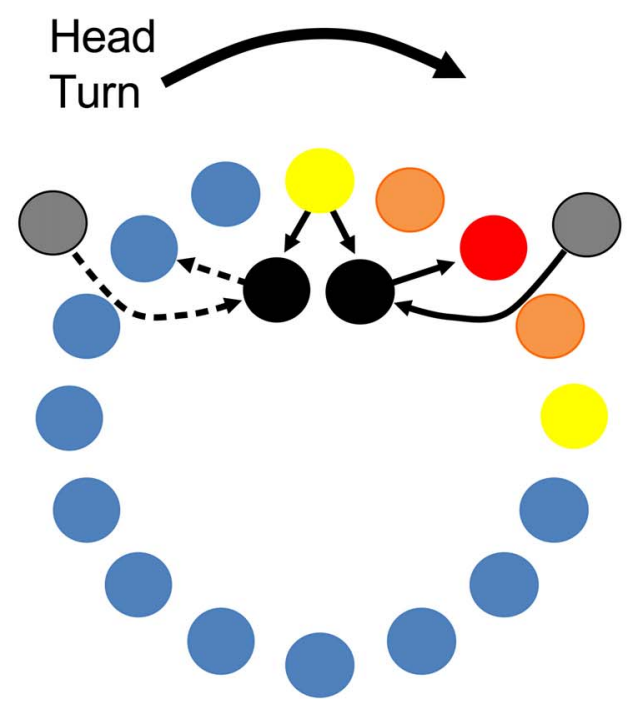

FIGURE 3 | (A) Components of a typical attractor network model of HD signal generation (e.g., Skaggs et al., 1995; Redish et al., 1996; McNaughton et al., 2006). In general, most attractor network models conceptually arrange $\mathrm{HD}$ cells in a circle or ring with each HD cell (colored circles) positioned according to their corresponding preferred tuning direction. Each HD cell sends strong excitatory axons to nearby neurons, and weaker excitatory inputs to more distant neurons. Inhibitory projections (not shown) within the network limit net activity resulting in a focused point, or a "hill," of high activity (warm colors). Movement of the activity hill corresponding to an animal's head movements is achieved by two additional neural signals: one that is sensitive to changes in an animal's angular head velocity (AHV) (gray circle), and another that conjunctively encodes current $\mathrm{HD} \times \mathrm{AHV}$ (black circle). These latter cells are either sensitive to right head turns and project to the right of the outer ring to which they receive input, or are sensitive to leftward head turns and project to the left of the ring to which they receive input. (B) Following a head turn, conjunctive $\mathrm{HD} \times \mathrm{AHV}$ cells drive the activity hill in the appropriate HD. For example, a right head turn would engage $\mathrm{HD} \times$ AHV neurons that are specifically sensitive to clockwise head turns (solid arrows). These neurons would in turn activate HD cells to the right of the hill and drive activity to the animal's current HD. generation, but instead utilized tetrodotoxin to temporarily inactivate vestibular hair cells. In short, postsubicular HD cells were recorded before and after vestibular inactivation, and consistent with the earlier study, were found to be completely nondirectional during inactivation. Interestingly, vestibular inactivation also disrupted the location-specific firing of hippocampal place cells (see also Russell et al., 2003), indicating that both HD and place cell systems require vestibular input. Because it appears that grid cells require input from HD cells in the anterodorsal thalamus (Clark et al., 2011), disrupting the HD signal via vestibular manipulations would also likely disrupt grid cell firing patterns in MEC and other limbic areas. The results of 

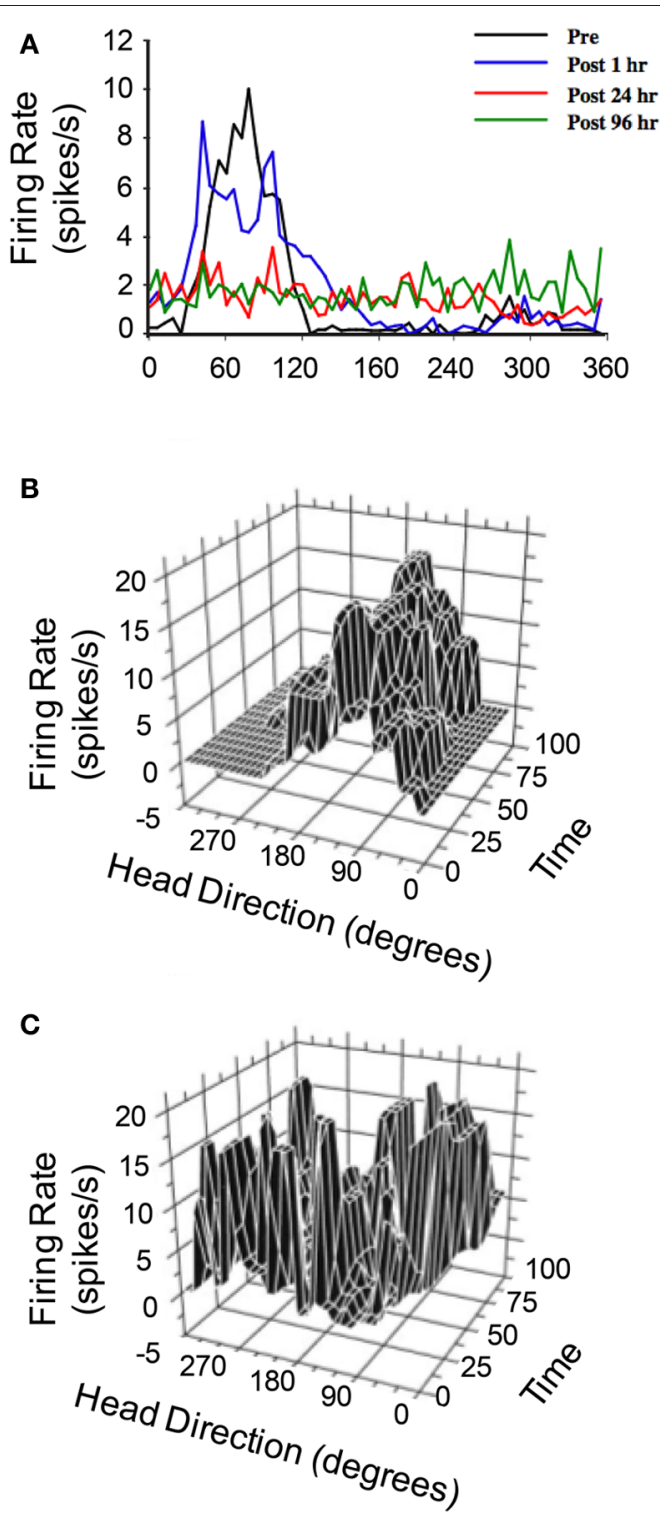

FIGURE 4 | (A) Responses of anterodorsal thalamic HD cells to sodium arsanilate lesions of the vestibular labyrinth (from Stackman and Taube, 1997). In general, disruption of the vestibular labyrinth abolished HD tuning shortly after the lesion and persisted up to $96 \mathrm{~h}$ after the lesion during which the cell was monitored. (B,C) $3 D$ plot of firing rate and $\mathrm{HD}$ as a function of time in epochs of $5 \mathrm{~s}$ duration of a distinct anterodorsal thalamic HD cell recorded before vestibular lesion (B) and a non-directional anterodorsal thalamic burst cell recorded after vestibular lesion (C). For both plots, unit activity was recorded over 8 min sessions, during which the rat foraged in a cylindrical apparatus. The post-lesion bursty cell depicted in (C) exhibited a characteristic pattern of intermittent high firing rate events that were neither related to the rat's HD nor temporally organized. Plots in (A-C) are modified from Stackman and Taube (1997).

Stackman et al. (2002), however, did not shed light on the issue of why burst activity was absent in their recordings after vestibular disruption. Moreover, because inactivation and permanent lesion techniques produce a general disruption to hair cells throughout the vestibular labyrinth (Chen et al., 1986), and even produce some damage to the 8th cranial nerve (Anniko and Wersäll, 1976), it remained unclear exactly where the origin of the impairments resided in the vestibular system.

The vestibular labyrinth is composed of the semicircular canals and the otolith organs, which provide information regarding angular and linear head acceleration, respectively. In an attempt to determine which of these vestibular components are essential for HD signal generation, Muir et al. (2009) occluded the semicircular canals bilaterally in chinchillas, a species of rodent that has large and easily accessible semicircular canals. Overall, the authors reported that anterodorsal thalamic HD cells recorded before semicircular canal occlusion lost all semblance of directional responding after occlusion. Importantly, and in contrast with the results of Stackman and Taube (1997), Muir et al. found that HD cells displayed bursty activity after semicircular canal occlusion. These "bursty" cells had the appearance of HD cells passing through their preferred directions when listened to through a loudspeaker, but unlike HD cells, they were completely uncorrelated with the animal's $\mathrm{HD}$, even at brief time intervals (Figure 5). Bursty cells also showed very little accommodation, and were non-periodic; they fired in random intervals throughout the recording session. Thus, it was postulated that bursting activity represented $\mathrm{HD}$ cells that were disconnected from their primary driving input (i.e., vestibular), and in contrast to the results of Stackman and Taube (1997), these findings appeared to support the attractor network scheme of HD circuit organization. This general conclusion was also substantiated by a number of additional observations. First, the duration of bursting activity was dependent on movement velocity-with faster rotations resulting in shorter burst durations, a finding that corresponds to normal HD cells as they pass through their preferred firing directions. Second, the percentage of spikes during bursts and the percentage of samples that contained bursts were similar between bursty cells and HD cells. Finally, in sessions in which two bursty cells were recorded simultaneously, the temporal order in which the bursts occurred was contingent on the animal's direction of rotation (Figures 5C and 6), just as an attractor network would predict. This latter observation is particularly interesting because it suggests that the general network organization remained intact following canal occlusion.

In a complimentary study conducted by Yoder and Taube (2009) that investigated the role of the otolith organs in HD cell activity, anterodorsal thalamic activity was monitored in otoconia deficient tilted mice (Lane, 1986), a transgenic mouse line that specifically have a disrupted sense of linear acceleration and head tilt. Surprisingly, Yoder and Taube (2009) identified a number of directionally tuned cells in the anterodorsal thalamus of tilted mice. For the most part, however, these HD cells demonstrated less robust directional firing compared to control mice, and were in many cases directionally unstable during recording sessions (i.e., the preferred direction of cells would drift over time). Consistent with Muir et al. a small number of bursty cells were identified in tilted mice, but not in control mice. Importantly, bursty cell activity was not observed simultaneously with neurons displaying sharp directional tuning, and the temporal order of simultaneously recorded bursty cells remained in register with one another depending on the direction of head rotation. This latter observation again supports the conclusion that the network 

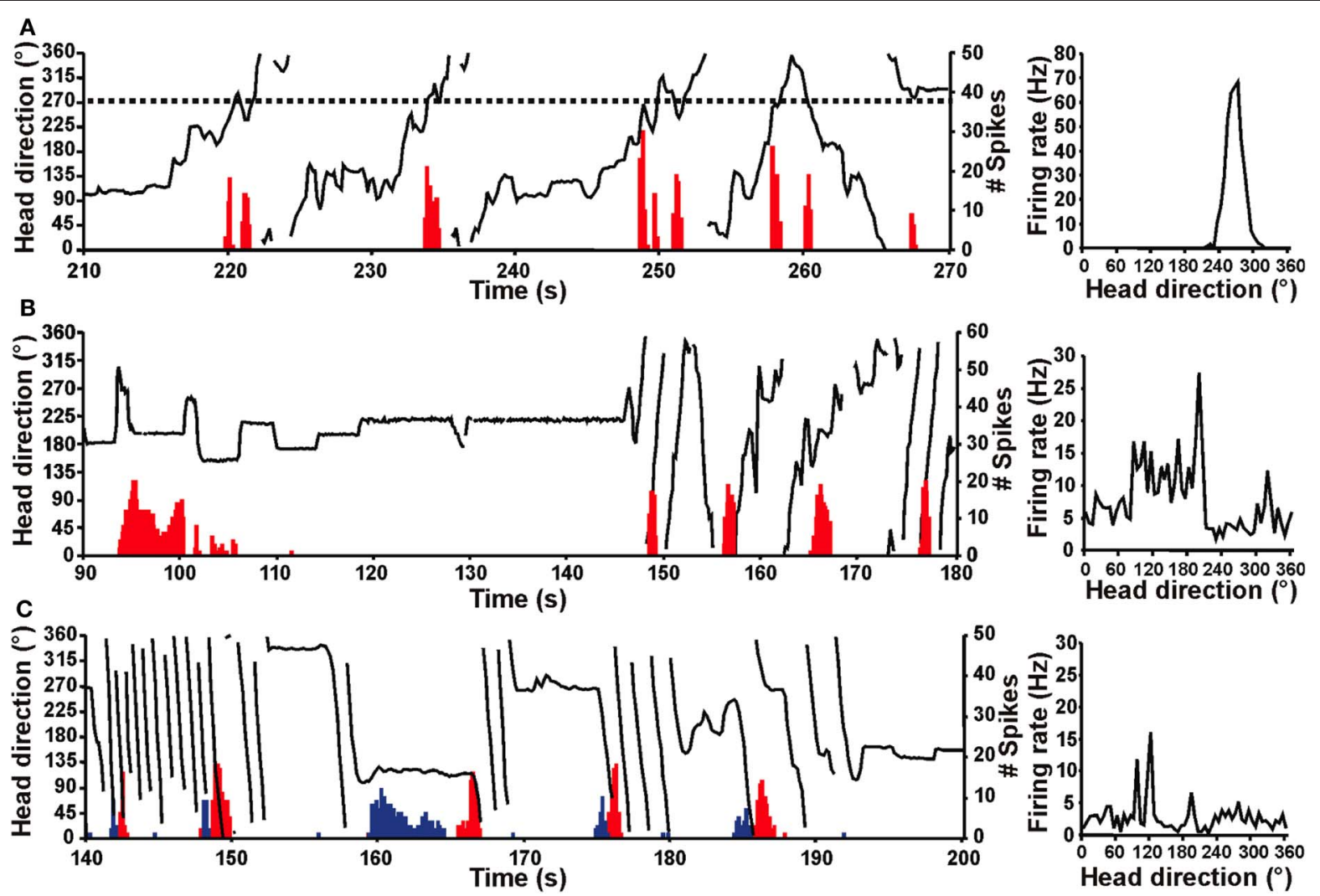

FIGURE 5 | Firing of normal HD and bursty cells over time (red histogram) relative to the chinchilla's HD (black line) for portions of an $\mathbf{8} \mathbf{~ m i n}$ recording session in a high-walled gray cylinder (left panels). Corresponding firing rate $\times \mathrm{HD}$ plots (right panels) for the cell shown at the left. (A) HD cell from a control chinchilla. The dotted line (left panel) represents the cell's preferred firing direction at $\sim 270^{\circ}$ and this cell consistently fired at a high rate whenever the animal's head pointed at $270^{\circ}$ (i.e., when the dotted line intersects the HD plot). The firing rate $\times$ HD plot for the control chinchilla (right panel) shows a clear, single-peaked function at $\sim 270^{\circ}$ that matches the preferred firing direction in the plot at left.

(B,C) Bursty cells from canal-plugged chinchillas. Note that the bursty cell in
(B) fired in bursts similar to an HD cell in a control animal, but there was no consistent relationship between the animal's HD and the occurrence of bursts. This absence of a relationship is particularly evident in the bursty cell's irregular firing rate $\times \mathrm{HD}$ function (right panel). (C) The plot on the left shows two simultaneously recorded bursty cells (cell 1, red; cell 2, blue). As in (B), the duration of the burst was related to the velocity of the animal's head movement for both cells shown. In addition, the order of firing for the two cells was dependent upon the direction of movement (i.e., CW vs. CCW), where the animal was making almost exclusively CW movements during the periods of rapid rotation shown. The firing rate $\times \mathrm{HD}$ plot for cell 2 is shown in the right panel. Panels (A-C) are from Muir et al. (2009). organization remained intact, but accurate updating via velocity information was specifically impaired. Together, the results of Yoder and Taube suggested that the otolith organs were not necessary for the generation of the directional signal, but are critical for their stability and the robustness of the signal. Thus, when considered with the canal-plugging findings of Muir et al., the experiments suggest that only the semicircular canals are necessary for HD cell generation in the anterodorsal thalamus.

The bursty activity identified in the experiments by Muir et al. and in Yoder and Taube provided strong support for the attractor network hypothesis. Nevertheless, the failure to identify bursty activity in populations of HD cells after vestibular damage, as was the case in the Stackman and Taube (1997) study, has posed a challenge to this general conclusion. Muir et al. (2009) argued that the difference between these studies might be related to the amount of time between vestibular damage and cellular recording. While Stackman and Taube (1997) continued their recording sessions shortly after sodium arsanilate damage $(1 \mathrm{~h})$, Muir et al. waited 1-2 weeks for recovery before anterodorsal thalamic neurons were reassessed for directional activity. Stackman and Taube continued recording cellular activity within the anterodorsal thalamus for up to $96 \mathrm{~h}$ after the lesion, but in no cases were bursty cells recorded within this time period. This difference may be relevant because secondary vestibular neurons, which normally have high resting firing rates (mean: $\sim 35$ spikes/s), return to only $50 \%$ of their baseline-firing rate after vestibular labyrinthectomy, and tonic activity of these neurons returns to pre-lesion levels only after 1 week (Ris and Godaux, 1998). Thus, Stackman and Taube monitored HD cell activity during a period of depressed tonic activity within the vestibular nuclei, suggesting that tonic firing by secondary vestibular neurons might underlie bursting activity.

\section{GENERATIVE CIRCUIT WITHIN THE HD CELL SYSTEM}

The work summarized thus far suggests that HD cells likely adopt bursty firing characteristics following vestibular interventions (Muir et al., 2009; Yoder and Taube, 2009). Preliminary 


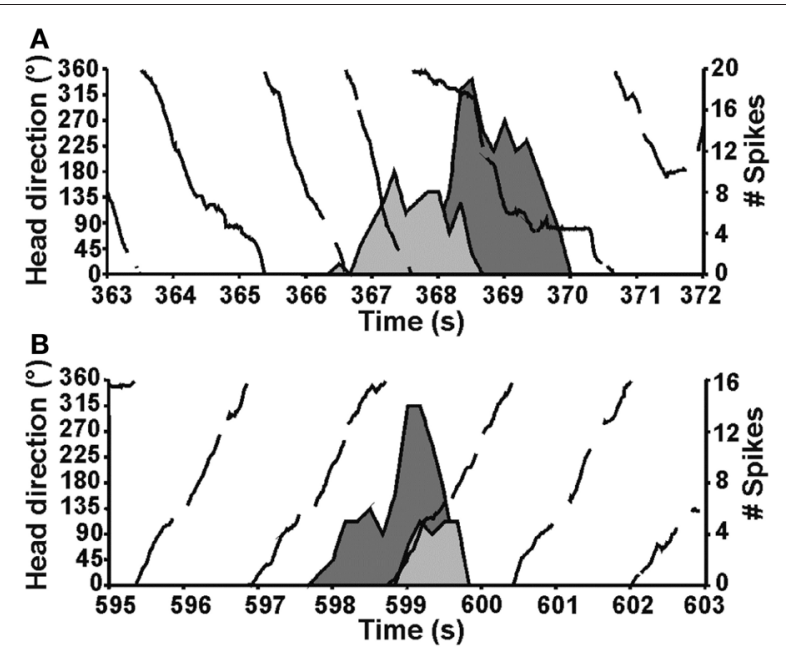

FIGURE 6 | The direction of the animal's movement strongly predicted the order of cell firing when pairs of HD or bursty cells were recorded simultaneously (HD, solid black line). Two different episodes are shown for the same pair of cells. During an episode when the animal made CCW turns (top), cell 1 (dark gray fill) fired a burst before cell 2 (light gray fill). In contrast, during an episode with $\mathrm{CW}$ head turns (bottom), cell 1 fired after cell 2. Plots in (A,B) are from Muir et al., 2009.

work from our laboratory has also corroborated these observations following lesions of putative vestibular relay centers such as the supragenual nucleus (Clark and Taube, unpublished observations). In contrast to these studies, however, Bassett et al. (2007) did not identify bursting activity in the anterodorsal thalamus of animals with bilateral lesions of the dorsal tegmental nuclei or lateral mammillary nuclei (see also Blair et al., 1998, 1999). Expanding on the interpretation that bursty activity after vestibular damage reflects an attractor network uncoupled from external vestibular input, these latter observations may constitute evidence that the HD signal and an attractor-based architecture resides in the reciprocal connectivity of the dorsal tegmental and lateral mammillary nuclei (Allen and Hopkins, 1989; Hayakawa and Zyo, 1989; Taube, 1998, 2007; Sharp et al., 2001a; Blair and Sharp, 2002).

The earliest support for the hypothesis above came from studies showing that both the lateral mammillary and dorsal tegmental nuclei contain populations of HD cells (Blair et al., 1998; Stackman and Taube, 1998; Sharp et al., 2001b), although with relatively smaller proportions reported in the dorsal tegmental nuclei compared to other diencephalic and telencephalic structures (reviewed in Taube and Bassett, 2003). Several anatomical studies also support the hypothesis, as both regions occupy a pivotal position between vestibular and landmark processing systems. Most notable among the vestibular system projections are the supragenual nuclei and nucleus prepositus hypoglossi (Figure 2; Brown et al., 2005; Biazoli et al., 2006); the latter of these two regions is thought to be the site of the neural integrator for the vestibulo-occular reflex (Robinson, 1989). Projections stemming from the nucleus prepositus hypoglossi are largely restricted to the dorsal tegmental nuclei (Brown et al., 2005; Biazoli et al., 2006), whereas output from the supragenual nuclei reaches all levels of the tegmento-mammillary pathway. These latter projections, however, are topographically organized such that output to the lateral mammillary nucleus is directed mostly ipsilateral, and output to the dorsal tegmental nucleus is directed largely to the contralateral side (Biazoli et al., 2006). The lateral mammillary nuclei also receive prominent projections from the postsubiculum (Shibata, 1989), suggesting that landmark information is integrated at this subcortical level (Yoder et al., 2011a).

Perhaps the strongest support for the hypothesis above comes from the findings that both the dorsal tegmental and lateral mammillary nuclei contain neurons sensitive to an animal's angular head velocity (Figure 7) (Blair et al., 1998; Stackman and Taube, 1998; Bassett and Taube, 2001; Sharp et al., 2001b). Indeed, 75\% of the neurons in the dorsal tegmental nuclei code for angular head velocity, suggesting that the structure has a prominent role in self-movement cue processing. Bassett and Taube (2001) observed two types of angular velocity cells in this region: one that increased its firing rate proportionately to the speed to which the animal turned its head in either direction (Figure 7A) (i.e., clockwise or counterclockwise), and another that fires only when an animal turns its head in one direction (Figures 7B,C). These cells were termed symmetric and asymmetric angular velocity cells, respectively. While the symmetric subtype accounted for $\sim 50 \%$ of the total cells in the dorsal tegmental nuclei, asymmetric angular velocity neurons accounted for $\sim 25 \%$ of the total
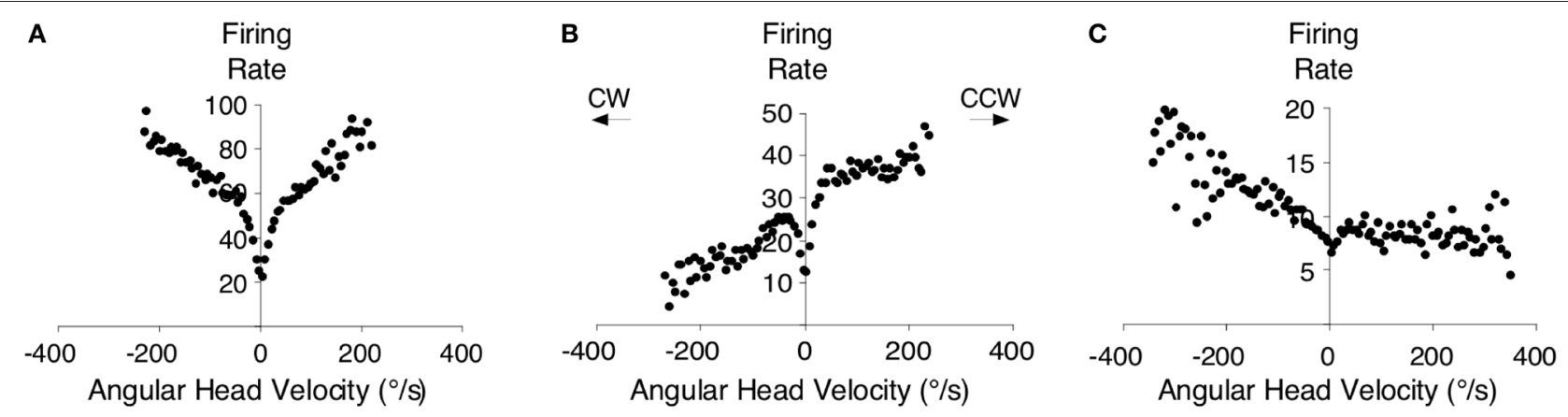

FIGURE 7 | An example of a symmetric angular head velocity cell is shown in (A) and representative examples of asymmetric angular head velocity cells are shown in (B,C). Clockwise (CW) and counter-clockwise (CCW) directions are as indicated. Plots in (A-C) are from Bassett and Taube (2001). 
population. Interestingly, most asymmetric cells were localized in the hemisphere opposite the preferred tuning direction, suggesting some lateralization of cellular activity within the HD cell circuit. Angular velocity cells within the lateral mammillary nuclei constitute a smaller overall percentage $(\sim 43 \%)$ compared to the dorsal tegmental nuclei $(\sim 75 \%)$, however only the symmetric variety is found within this region. Furthermore, the properties of angular velocity cells are very similar between both brain regions. Asymmetric coding of angular velocity cells is consistent with the early ring attractor models, but the findings of symmetric subtypes have not received similar attention (but see Stratton et al., 2010). Given the high proportion of symmetric cells, future computational work should include networks with both asymmetric and symmetric subtypes.

One important issue to consider here is how the angular head velocity signal is derived within the tegmento-mammillary circuit? It is widely assumed that this signal is generated in large part from the vestibular system, and preliminary data from our laboratory appears to support this view, i.e., tetrodotoxin inactivation of the vestibular labyrinth significantly reduces angular head velocity sensitivity of neurons in the dorsal tegmental nucleus (Kosty and Taube, unpublished observations). Sharp et al. (2001b) demonstrated, however, that some angular velocity cells become "silent" when an animal is passively rotated while being handled by the experimenter. Although Sharp et al. reported that this was the case for only 5 of the 12 identified angular velocity cells in the study, this finding suggests that other sources of self-movement signals may play a role in generating angular velocity sensitivity. Subsequent work by Sharp et al. (2006) suggested that direct projections from the lateral habenula/interpeduncular nucleus to the dorsal tegmental nuclei might constitute a non-vestibular (motor) pathway. This possibility is supported by the identification of small proportions of angular and linear velocity modulated neurons in the habenula and interpeduncular nucleus (Sharp et al., 2006), as well as the finding that damage to the interpeduncular nucleus disrupts HD cell stability in the anterodorsal thalamus (Clark et al., 2009).

The possibility that the tegmento-mammillary circuit is the site of $\mathrm{HD}$ signal generation is also particularly attractive when considering the architecture of an attractor network. As noted above, network models typically rely on a set of recurrent excitatory connections to sustain the activity hill in a stable state (see Figure 3). They also rely on inhibitory connections to prevent the excitation of cells outside the current firing direction. The lateral mammillary and dorsal tegmental nuclei could conceivably contain this type of architecture because the dorsal tegmental nuclei to lateral mammillary nuclei projections are largely inhibitory (Gonzalo-Ruiz et al., 1993; Wirtshafter and Stratford, 1993), and the reciprocal projections are excitatory (Figure 2) (Hayakawa and Zyo, 1990). This pattern of connectivity has lent itself well to the interpretation that projecting neurons in the lateral mammillary region, presumably from HD cells, activate their inhibitory targets in the dorsal tegmental nuclei, which consequently inhibit their out-of-direction neighbors (Sharp et al., 2001a). Given that the reciprocal connections of the dorsal tegmental nuclei and nucleus prepositus hypoglossi also have an inhibitory/excitatory relationship, a similar conceptual scheme could be arranged between these nuclei as well. Nevertheless, very little is known about neural activity in the rodent nucleus prepositus in freely-moving animals [cf., McFarland and Fuchs, 1992, recorded from head fixed monkeys that were passively rotated sinusoidally and/or had to eye track a small target that moved horizontally. The authors found three types of neurons-two of which responded with eye movements, but were insensitive to vestibular stimulation, and a third type which was sensitive to both eye movement and vestibular stimulation]. Thus, whether this structure plays a significant role in HD signal computations is presently unclear.

Another theoretical prediction made by attractor models is the notion that conjunctive neurons that code for both HD and angular head velocity are responsible for driving the activity hill in the appropriate direction along the ring network (Figure 3). Consistent with this prediction, studies have identified small populations of these conjunctive neurons in the dorsal tegmental nuclei (11\%, Bassett and Taube, 2001; 13\%, Sharp et al., 2001b). However, it is important to point out that these putative conjunctive neurons fired across a broader range of directions and are, therefore, more coarsely modulated relative to the "classic" HD cell populations in other brain areas. Thus, it is unclear how such small populations of coarsely modulated conjunctive cells could be utilized to accurately update current HD within an attractor network.

One issue that has remained unexplored is the possibility that multiple generative circuits exist within the HD cell system. For instance, the connectivity within the postsubiculum and the inhibitory projections from this area could in principal support an attractor network (van Haeften et al., 1997). Arguing against this possibility, however, are the findings that neurons within the postsubiculum provide only a modest representation of angular head velocity, with $\sim 10 \%$ responding to this movement characteristic (Sharp, 1996). Neurons with angular head movement correlates have been identified in the rat parietal cortex (McNaughton et al., 1993), but as noted earlier, lesions of this region do not abolish directional tuning in the anterior thalamus (Calton et al., 2008), and inactivation of the structure does not impair directional firing "downstream" in the medial entorhinal cortex (Whitlock et al., 2010). Furthermore, lesions of the anterodorsal thalamus (Goodridge and Taube, 1997) or lateral mammillary nuclei (Sharp and Koester, 2008) completely abolish HD cell tuning in the postsubiculum, with no reports of bursting activity by postsubicular neurons after these lesions. This latter finding, in particular, suggests that HD cell generation most likely follows a path from the vestibular nuclei $\rightarrow$ supragenual/prepositus nuclei $\rightarrow$ dorsal tegmental nuclei $\rightarrow$ lateral mammillary nuclei $\rightarrow$ anterodorsal $\rightarrow$ thalamus parahippocam$\mathrm{pal} /$ retrosplenial cortex.

One potential caveat to the hypotheses outlined above is the recent work that has identified populations of directionally tuned neurons in the anteroventral thalamus (Yoganarasimha et al., 2006; Tsanov et al., 2011); a thalamic region that does not receive direct input from the lateral mammillary nuclei (Shibata, 1992). The anteroventral thalamus receives one of its major inputs from the medial mammillary bodies (Shibata, 1992), which do not contain neurons with HD firing characteristics 
(Sharp and Turner-Williams, 2005). One possibility is that anteroventral thalamic neurons receive their directional sensitivity through descending inputs from the retrosplenial cortex (Wyss and van Groen, 1992) or postsubiculum (van Groen and Wyss, 1990). In this scenario, the pathway would follow from anterodorsal thalamus $\rightarrow$ retrosplenial/postsubiculum $\rightarrow$ anteroventral thalamus. Alternatively, there could be a direct intra-thalamic projection from the anterodorsal to anteroventral region. Although there is no evidence for this latter projection, these connections are likely difficult to detect with current anatomical techniques, given that both nuclei lie adjacent to one another. HD cells have also been identified in the laterodorsal thalamus (Mizumori and Williams, 1993), but similar to the anteroventral thalamus, HD cells have not been identified in the subcortical afferents to the laterodorsal thalamus (Cooper et al., 1998) and lesions of the structure do not abolish HD cell activity in the postsubiculum (Golob et al., 1998). The laterodorsal nuclei receive large inputs from the retrosplenial cortex (Shibata, 2000) and postsubiculum (van Groen and Wyss, 1990), and again, it is possible that the HD signal within the laterodorsal thalamus is conveyed from these regions. Collectively, the studies summarized above suggest that a number of parallel processing pathways likely exist at the cortical-thalamic level of the HD cell circuit, which overlays the general hierarchical organization. Future work should be directed at identifying the critical pathways within these cortical-thalamic loops, and to better understand the precise role these parallel pathways play in shaping the HD cell signal.

\section{REFERENCES}

Allen, G. V., and Hopkins, D. A. (1989). Mammillary body in the rat: topography and synaptology of projections from the subicular complex, prefrontal cortex, and midbrain tegmentum. J. Comp. Neurol. 286, 311-336.

Anniko, M., and Wersäll, J. (1976). Afferent and efferent nerve terminal degeneration in the guinea-pig cochlea following atoxyl administration. Acta Otolaryngol. 82, 325-336.

Bassett, J. P., and Taube, J. S. (2001). Neural correlates for angular head velocity in the rat dorsal tegmental nucleus. J. Neurosci. 21, 5740-5751.

Bassett, J. P., Tullman, M. L., and Taube, J. S. (2007). Lesions of the tegmentomammillary circuit in the head direction system disrupt the head direction signal in the anterior thalamus. J. Neurosci. 27, 7564-7577.

Biazoli, C. E. Jr., Goto, M., Campos, A. M., and Canteras, N. S. (2006). The supragenual nucleus: a putative relay station for ascending vestibular signs to head direction cells. Brain Res. 1094, 138-148.

Blair, H. T., and Sharp, P. E. (2002). "Functional organization of the rat head-direction circuit," in

\section{CONCLUSIONS}

The present review summarized recent work that has been directed toward understanding the functional organization of the HD cell system, and much of this work supports three general conclusions. First, a large body of data strongly suggests that the HD cell signal is hierarchically organized and is primarily generated within subcortical circuits. This highly processed directional signal is then conveyed to cortical and parahippocampal regions through inputs from the anterior thalamus, including the anterodorsal thalamus and possibly the anteroventral region. A second general conclusion is that the identification of bursty activity within the HD cell network after vestibular damage appears to support the attractor network hypothesis of HD signal generation. The strongest evidence for this conclusion is derived from the fact that the temporal relationship between neurons is preserved after vestibular damage (Muir et al., 2009; Yoder and Taube, 2009) and is strongly correlated with an animal's direction of movement (i.e., right vs. left turns). Third, the observation of intermittent burst activity after vestibular damage, but not after dorsal tegmental or lateral mammillary damage is consistent with the hypothesis that the attractor architecture resides within the reciprocal connections of the tegmento-mammillary circuit.

\section{ACKNOWLEDGMENTS}

This work was supported through grants from the National Institute of Health (NS053907, DC009318) to Jeffrey S. Taube and a postgraduate fellowship from the National Sciences and Engineering Research Council of Canada to Benjamin J. Clark.

direction cell network. J. Neurosci. 23, 9719-9731.

Calton, J. L., Turner, C. S., Cyrenne, D. L., Lee, B. R., and Taube, J. S. (2008). Landmark control and updating of self-movement cues are largely maintained in head direction cells after lesions of the posterior parietal cortex. Behav. Neurosci. 122, 827-840.

Chen, Y. C., Pellis, S. M., Sirkin, D. W., Potegal, M., and Teitelbaum, P. (1986). Bandage backfall: labyrinthine and non-labyrinthine components. Physiol. Behav. 37, 805-814.

Clark, B. J., Bassett, J. P., Wang, S., and Taube, J. S. (2010). Impaired head direction cell representation in the anterodorsal thalamus after lesions of the retrosplenial cortex. J. Neurosci. 30, 5289-5302.

Clark, B. J., Sarma, A., and Taube, J. S. (2009). Head direction cell instability in the anterior dorsal thalamus after lesions of the interpeduncular nucleus. J. Neurosci. 29, 493-507.

Clark, B. J., and Taube, J. S. (2011). Intact landmark control and angular path integration by head direction cells in the anterodorsal thalamus after lesions of the medial entorhinal cortex. Hippocampus 21, 767-782.

Clark, B. J., Valerio, S., and Taube, J. S. (2011). Disrupted grid and head direction cell signal in the entorhinal cortex and parasubiculum after lesions of the head direction system. Program No. 729.112011 Neuroscience Meeting Planner. Washington, DC: Society for Neuroscience. [Online].

Cooper, B. G., Miya, D. Y., and Mizumori, S. J. (1998). Superior colliculus and active navigation: role of visual and non-visual cues in controlling cellular representations of space. Hippocampus 8, 340-372.

Gallistel, C. R. (1990). The Organization of Learning. Cambridge, MA: MIT Press.

Golob, E. J., and Taube, J. S. (1997). Head direction cells and episodic spatial information in rats without a hippocampus. Proc. Natl. Acad. Sci. U.S.A. 94, 7645-7650.

Golob, E. J., and Taube, J. S. (1999). Head direction cells in rats with hippocampal or overlying neocortical lesions: evidence for impaired angular path integration. J. Neurosci. 19, 7198-7211.

Golob, E. J., Wolk, D. A., and Taube, J. S. (1998). Recordings 
of postsubiculum head direction cells following lesions of the laterodorsal thalamic nucleus. Brain Res. 780, 9-19.

Gonzalo-Ruiz, A., Sanz-Anquela, J. M., and Spencer, R. F. (1993). Immunohistochemical localization of GABA in the mammillary complex of the rat. Neuroscience 54, 143-156.

Goodridge, J. P., Dudchenko, P. A., Worboys, K. A., Golob, E. J., and Taube, J. S. (1998). Cue control and head direction cells. Behav. Neurosci. 112, 749-761.

Goodridge, J. P., and Taube, J. S. (1997). Interaction between postsubiculum and anterior thalamus in the generation of head direction cell activity. J. Neurosci. 17, 9315-9330.

Hafting, T., Fyhn, M., Molden, S., Moser, M. B., and Moser, E. I. (2005). Microstructure of a spatial map in the entorhinal cortex. Nature 436, 801-806.

Hayakawa, T., and Zyo, K. (1989). Retrograde double-labeling study of the mammillothalamic and the mammillotegmental projections in the rat. J. Comp. Neurol. 284, 1-11.

Hayakawa, T., and Zyo, K. (1990). Fine structure of the lateral mammillary projection to the dorsal tegmental nucleus of Gudden in the rat. $J$. Comp. Neurol. 298, 224-236.

Johnson, A., Seeland, K., and Redish, A. D. (2005). Reconstruction of the postsubiculum head direction signal from neural ensembles. Hippocampus 15, 86-96.

Kerr, K. M., Agster, K. L., Furtak, S. C., and Burwell, R. D. (2007). Functional neuroanatomy of the parahippocampal region: the lateral and medial entorhinal areas. Hippocampus 17, 697-708.

Lane, P. (1986). Tilted (tlt). Mouse News Lett. 75, 28.

Lever, C., Burton, S., Jeewajee, A., O'Keefe, J., and Burgess, N. (2009). Boundary vector cells in the subiculum of the hippocampal formation. J. Neurosci. 29, 9771-9777.

McFarland, J. L., and Fuchs, A. F. (1992). Discharge patterns in nucleus prepositus hypoglossi and adjacent medial vestibular nucleus during horizontal eye movement in behaving macaques. J. Neurophysiol. 68, 319-332.

McNaughton, B. L., Barnes, C. A., Gerrard, J. L., Gothard, K., Jung, M. W., Knierim, J. J., Kudrimoti, H., Qin, Y., Skaggs, W. E., Suster, M., and Weaver, K. L. (1996). Deciphering the hippocampal polyglot: the hippocampus as a path integration system. J. Exp. Biol. 199, 173-185.
McNaughton, B. L., Battaglia, F. P., Jensen, O., Moser, E. I., and Moser, M. B. (2006). Path integration and the neural basis of the 'cognitive map'. Nat. Rev. Neurosci. 7, 663-678.

McNaughton, B. L., Chen, L., and Markus, E. (1991). "Dead reckoning," landmark learning, and the sense of direction: a neurophysiological and computational hypothesis. J. Cogn. Neurosci. 3, 190-202.

McNaughton, B. L., Mizumori, S. J., Barnes, C. A., Leonard, B., Marquis, M., and Green, E. (1993). Cortical representation of motion during unrestrained spatial navigation in the rat. Cereb. Cortex 4, 27-39.

Mizumori, S. J., and Williams, J. D. (1993). Directionally selective mnemonic properties of neurons in the lateral dorsal nucleus of the thalamus of rats. J. Neurosci. 13, 4015-4028.

Moser, E. I., Kropff, E., and Moser, M. B. (2008). Place cells, grid cells, and the brain's spatial representation system. Ann. Rev. Neurosci. 31, 69-89.

Muir, G. M., Brown, J. E., Carey, J. P., Hirvonen, T. P., Della Santina, C. C., Minor, L. B., and Taube, J. S. (2009). Disruption of the head direction cell signal after occlusion of the semicircular canals in the freely moving chinchilla. J. Neurosci. 29, 14521-14533.

O’Keefe, J., and Dostrovsky, J. (1971). The hippocampus as a spatial map. Preliminary evidence from unit activity in the freely-moving rat. Brain Res. 34, 171-175.

O'Keefe, J., and Nadel, L. (1978). The Hippocampus as a Cognitive Map. Oxford, UK: Oxford University Press.

Papez, J. (1937). A proposed mechanism of emotion. Arch. Neurol. 38, 103-112.

Potegal, M. (1982). "Vestibular and neostriatal contributions to spatial orientation," in Spatial Abilities: Development and Physiological Foundations, ed M. Potegal (New York, NY: Academic Press), 361-387.

Ranck, J. B. Jr. (1984). Head direction cells in the deep layer of dorsal presubiculum in freely moving rats. Soc. Neurosci. Abstr. 10, 599.

Redish, A. D., Elga, A. N., and Touretzky, D. S. (1996). A coupled attractor model of the rodent head direction system. Netw. Comput. Neural Syst. 7, 671-685.

Ris, L., and Godaux, E. (1998). Neuronal activity in the vestibular nuclei after contralateral or bilateral labyrinthectomy in the alert guinea pig. J. Neurophysiol. 80, 2352-2367.
Robinson, D. A. (1989). Integrating with neurons. Annu. Rev. Neurosci. 12, 33-45.

Russell, N., Horii, A., Smith, P., Darlington, C., and Bilkey, D. (2003). Long-term effects of permanent vestibular lesions on hippocampal spatial firing. J. Neurosci. 23, 6490-6498.

Sargolini, F., Fyhn, M., Hafting, T., McNaughton, B. L., Witter, M. P., Moser, M. B., and Moser, E. I. (2006). Conjunctive representation of position, direction, and velocity in entorhinal cortex. Science 312, 758-762.

Savelli, F., Yoganarasimha, D., and Knierim, J. J. (2008). Influence of boundary removal on the spatial representations of the medial entorhinal cortex. Hippocampus 18, 1270-1282.

Sharp, P. E. (1996). Multiple spatial/behavioral correlates for cells in the rat postsubiculum: multiple regression analysis and comparison to other hippocampal areas. Cereb. Cortex 6, 238-259.

Sharp, P. E., and Koester, K. (2008). Lesions of the mammillary body region severely disrupt the cortical head direction, but not place cell signal. Hippocampus 18, 766-784.

Sharp, P. E., Blair, H. T., and Cho, J. (2001a). The anatomical and computational basis of the rat head-direction cell signal. Trends Neurosci. 24, 289-294.

Sharp, P. E., Tinkelman, A., and Cho, J. (2001b). Angular velocity and head direction signals recorded from the dorsal tegmental nucleus of Gudden in the rat: implications for path integration in the head direction cell circuit. Behav. Neurosci. 115, 571-588.

Sharp, P. E., and Turner-Williams, S. (2005). Movement-related correlates of single-cell activity in the medial mammillary nucleus of the rat during a pellet-chasing task J. Neurophysiol. 94, 1920-1927.

Sharp, P. E., Turner-Williams, S., and Tuttle, S. (2006). Movement-related correlates of single cell activity in the interpeduncular nucleus and habenula of the rat during a pelletchasing task. Behav. Brain Res. 166 55-70.

Shibata, H. (1989). Descending projections to the mammillary nuclei in the rat, as studied by retrograde and anterograde transport of wheat germ agglutinin-horseradish peroxidase. J. Comp. Neurol. 285, 436-452.

Shibata, H. (1992). Topographic organization of subcortical projections to the anterior thalamic nuclei in the rat. J. Comp. Neurol. 323, 117-127.

Shibata, H. (2000). Organization of retrosplenial cortical projections to the laterodorsal thalamic nucleus in the rat. Neurosci. Res. 38, 303-311.

Skaggs, W. E., Knierim, J. J., Kudrimoti, H. S., and McNaughton, B. L. (1995). "A model of the neural basis of the rat's sense of direction," in Advances in Neural Information Processing Systems, Vol. 7, eds G. Tesauro, D. S. Touretzky, and T. K. Leen (Cambridge, MA: MIT Press), 173-180.

Solstad, T., Boccara, C. N., Kropff, E., Moser, M. B., and Moser, E. I. (2008). Representation of geometric borders in the entorhinal cortex. Science 322, 1865-1868.

Stackman, R. W., Clark, A. S., and Taube, J. S. (2002). Hippocampal spatial representations require vestibular input. Hippocampus 12, 291-303.

Stackman, R. W., Golob, E. J., Bassett, J. P., and Taube, J. S. (2003). Passive transport disrupts directional path integration by rat head direction cells. J. Neurophysiol. 90, 2862-2874.

Stackman, R. W., and Taube, J. S. (1997). Firing properties of head direction cells in rat anterior thalamic neurons: dependence upon vestibular input. J. Neurosci. 17, 4349-4358.

Stackman, R. W., and Taube, J. S. (1998). Firing properties of rat lateral mammillary single units: head direction, head pitch, and angular head velocity. J. Neurosci. 18, 9020-9037.

Stratton, P., Wyeth, G., and Wiles, J. (2010). Calibration of the head direction network: a role for symmetric angular head velocity cells. J. Comput. Neurosci. 28, 527-538.

Taube, J. S. (1995). Head direction cells recorded in the anterior thalamic nuclei of freely moving rats. J. Neurosci. 15, 70-86.

Taube, J. S. (1998). Head direction cells and the neurophysiological basis for a sense of direction. Prog. Neurobiol. 55, 225-256.

Taube, J. S. (2007). The head direction signal: origins and sensory-motor integration. Annu. Rev. Neurosci. 30, 181-207.

Taube, J. S., and Bassett, J. P. (2003). Persistent neural activity in head direction cells. Cereb. Cortex 13, 1162-1172.

Taube, J. S., and Burton, H. L. (1995). Head direction cell activity monitored in a novel environment and during a cue conflict situation. J. Neurophysiol. 74, 1953-1971. 
Taube, J. S., Muller, R. U., and Ranck, J. B. Jr. (1990a). Headdirection cells recorded from the postsubiculum in freely moving rats. I. Description and quantitative analysis. J. Neurosci. 10, 420-435.

Taube, J. S., Muller, R. U., and Ranck, J. B. Jr. (1990b). Headdirection cells recorded from the postsubiculum in freely moving rats. II. Effects of environmental manipulations. J. Neurosci. 10, 436-447.

Tsanov, M., Chah, E., Vann, S., Reilly, R., Erichsen, J., Aggleton, J., and O'Mara, S. (2011). Theta-modulated head direction cells in the rat anterior thalamus. J. Neurosci. 31, 9489-9502.

van Groen, T., and Wyss, J. M. (1990). The postsubicular cortex in the rat: characterization of the fourth region of the subicular cortex and its connections. Brain Res. 529, 165-177.

van Haeften, T., Wouterlood, F., Jorritsma-Byham, B., and Witter,
M. P. (1997). GABAergic presubicular projections to the medial entorhinal cortex of the rat. J. Neurosci. 17, 862-874.

Whitlock, J. R., Derdikman, D., Pfuhl, G., Moser, M. B., and Moser, E. I. (2010). Effects of parietal cortical inactivation on representations in entorhinal cortex. Program No. 101.13. 2010 Neuroscience Meeting Planner. San Diego, CA: Society for Neuroscience. [Online].

Wirtshafter, D., and Stratford, T. R. (1993). Evidence for GABAergic projections from the tegmental nuclei of Gudden to the mammillary body in the rat. Brain Res. 630, 188-194.

Wyss, J. M., and van Groen, T. (1992). Connections between the retrosplenial cortex and the hippocampal formation: a review. Hippocampus 1, $1-11$.

Yoder, R., and Taube, J. S. (2008). The postsubiculum provides visual landmark control to the head direction signal at the lateral mammillary nuclei. Program No. 90.9. 2008 Neuroscience Meeting Planner.
Washington, DC: Society for Neuroscience. [Online].

Yoder, R., and Taube, J. S. (2009). Head direction cell activity in mice: robust directional signal depends on intact otolith organs. J. Neurosci. 29, 1061-1076.

Yoder, R. M., Clark, B. J., and Taube, J. S. (2011a). Origins of landmark encoding in the brain. Trends Neurosci. 34, 561-571.

Yoder, R. M., Clark, B. J., Brown, J. E., Lamia, M. V., Valerio, S., Shinder, M. E., and Taube, J. S. (2011b) Both visual and idiothetic cues contribute to head direction cell stability during navigation along complex routes. J. Neurophysiol. 105, 2989-3001.

Yoganarasimha, D., Yu, X., and Knierim, J. J. (2006). Head direction cell representations maintain internal coherence during conflicting proximal and distal cue rotations: comparison with hippocampal place cells. J. Neurosci. 26 , 622-631.

Zhang, K. (1996). Representation of spatial orientation by the intrinsic dynamics of the head-direction cell ensemble: a theory. J. Neurosci. 16, 2112-2126.

Conflict of Interest Statement: The authors declare that the research was conducted in the absence of any commercial or financial relationships that could be construed as a potential conflict of interest.

Received: 13 December 2011; accepted: 14 February 2012; published online: 20 March 2012.

Citation: Clark BJ and Taube JS (2012) Vestibular and attractor network basis of the head direction cell signal in subcortical circuits. Front. Neural Circuits 6:7. doi: 10.3389/fncir.2012.00007

Copyright (c) 2012 Clark and Taube.

This is an open-access article distributed under the terms of the Creative Commons Attribution Non Commercial License, which permits non-commercial use, distribution, and reproduction in other forums, provided the original authors and source are credited. 